\title{
Association of physical activity and appetite with visual function related to driving competence in older adults
}

\author{
Takafumi Ando*, Hiroyuki Sakai and Yuji Uchiyama*
}

\begin{abstract}
Background: Older people are at greater risk of traffic accidents, partially because of age-related declines in visual function, including reduced useful field of view (UFOV). However, lifestyle factors which cause age-related decline in UFOV remain poorly understood. We conducted a study to investigate whether physical activity and appetite status were related to UFOV test performance in healthy older adults.

Methods: Thirty community-dwelling older people (age $68.6 \pm 3.1$ years, 15 females) were enrolled in this study. Each participant completed the Council on Nutrition appetite questionnaire (CNAQ) and a UFOV test. They then wore a tri-axial accelerometer (Active style Pro HJA-350IT) for 3-6 consecutive days to objectively measure their PA in free-living conditions.

Results: Longer time spent in vigorous physical activity was significantly associated with better UFOV test performance when adjusted for age and accelerometer wear time (non-locomotive: $r=-0.435$, locomotive: $r=-0.449 ; n=25)$. In addition, male, but not female, participants with a higher CNAQ score had significantly better UFOV test performance in both an unadjusted model $(r=-0.560 ; n=15)$ and a model adjusted for age $(r=-0.635 ; n=15)$.
\end{abstract}

Conclusions: The results suggest that appetite status among males and time spent in high intensity PA are associated with visual function related to driving competence in older adults.

Keywords: Lifestyle habit, Physical activity, Accelerometry, Appetite, Driving safety, Useful field of view, Aging, Cognitive decline

\section{Background}

Elderly people are more at risk of traffic accidents. In Japan, fatal accident rate increases with age in elderly drivers [1] and pedestrians [2]. When navigating through a traffic environment, a road user is required to interpret traffic scenes and choose appropriate actions without premeditation. However, it is well known that various functions, including sensory, perceptual, cognitive, and motor functions, gradually decline as part of the normal aging process. Many researchers have therefore focused on the impact of such age-related functional decline on the risk of traffic accidents [3].

\footnotetext{
* Correspondence: t-ando@mosk.tytlabs.co.jp; uchiyama@mosk.tytlabs.co.jp Human Science Research Domain, Toyota Central R\&D Labs., Inc, 41-1 Yokomichi, Nagakute, Aichi 480-1192, Japan
}

The useful field of view (UFOV) assessment is widely accepted as a measure of visual function that predicts driving competence in older adults [4]. The UFOV test was originally designed to capture the age-related decline in the visual area over which necessary information can be obtained in a brief glance [5]. Subsequent retrospective [6], prospective [7], and interventional [8] studies demonstrated that visual function assessed using the UFOV test was associated with at-fault crash risk in older drivers. Although there was considerable variation in the stimulus displays and scoring methods of the UFOV assessments in the early studies, a standardized version $\left(\mathrm{UFOV}^{\circ}\right)$ is now commercially available. This standardized UFOV test includes three subtests: subtest 1 measures processing speed (discriminating stimuli presented in central vision), subtest 2 measures divided attention (subtest 1 with 
concurrent detection of a peripheral stimulus), and subtest 3 measures selective attention (subtest 2 with additional distractions). Recent studies $[9,10]$ have shown that the divided attention subtest may be an adequate measure of visual function related to driving competence in older adults. The aspects of visual functioning assessed by the divided attention component of the UFOV test include not only divided attention but also sensory, perceptual, and cognitive abilities.

The individual variation in visual function evaluated by the UFOV test is considerable and potentially critical for safe driving by older adults. However, the factors that cause this variation are not well understood. Recently, the beneficial effects of active lifestyles on functional health in the elderly have become apparent $[11,12]$. The results of three studies that investigated the relationship between physical activity (PA) and UFOV in older adults were inconsistent. Two studies found a significant association between PA and UFOV test performance [13, 14], but the other reported no association [15]. These observational studies used questionnaires to evaluate PA, which may not be a reliable or accurate method to assess PA $[16,17]$. In addition, these studies did not precisely evaluate the mode, intensity, and duration of PA.

Poor appetite in older adults could be another factor contributing to age-related cognitive decline. Age-related decrease in appetite, called "anorexia of aging", is considered a potential cause of malnutrition in older adults [18-20]. With respect to malnutrition and cognitive decline, several studies have reported that healthy dietary patterns in older adults were associated with less cognitive decline [21]. These previous studies imply that older adults with lower appetites have lower cognitive performance than those with higher appetites. In fact, Ohrmann et al. indicated that younger anorexia patients showed lower performance on a divided attention task than did healthy controls [22]. However, there is no direct evidence of the association between appetite and UFOV test performance in older adults.

We conducted a pilot study to investigate whether PA, assessed using a tri-axial accelerometer, was associated with UFOV test performance in healthy older individuals.
We investigated whether appetite status was related to UFOV test performance in older adults, using the Council on Nutrition appetite questionnaire (CNAQ) [23].

\section{Methods}

\section{Participants}

Thirty participants ( 15 females and 15 males, mean age $68.6 \pm 3.1$ years) enrolled in this study. Healthy older people aged between 65 and 74 years were recruited through local help-wanted magazines distributed in Nagoya, Japan, and the surrounding suburbs. All participants reported being free of eye diseases (glaucoma, cataract, and macular degeneration), severe lower back pain, gait difficulty, history of psychiatric disorders, diabetes mellitus, and photosensitive epilepsy. According to results of the mini-mental state examination, no participants showed severe general cognitive decline (mean score: $28.3 \pm 1.7$, range: $24-30$ ). In addition, no participants had regular water-based exercise, such as swimming.

Each participant provided written informed consent before enrollment. The study protocol was approved by the institutional ethics committee of Toyota Central Research and Development Laboratories, Inc. This study was conducted between late September 2014 and early November 2014.

\section{UFOV test}

Participants completed a computer-controlled UFOV assessment seated in front of an LCD monitor (FG2421, EIZO Corporation, Ishikawa, Japan) at a visual distance of $60 \mathrm{~cm}$. The spatial and temporal resolutions of the monitor were $1280 \times 1024$ pixels and $100 \mathrm{~Hz}$, respectively. The UFOV assessment was controlled by Psychtoolbox software with GNU Octave 3.2.4, using the Linux operating system (Ubuntu 12.04 LTS).

We adopted the divided attention subtest of the UFOV assessment (Fig. 1), which had been proposed in earlier research [24]. The appearance of this UFOV test was different from the commercial version. We confirmed that performance on this test was a good predictor of driving competence in older adults in our previous study [10].

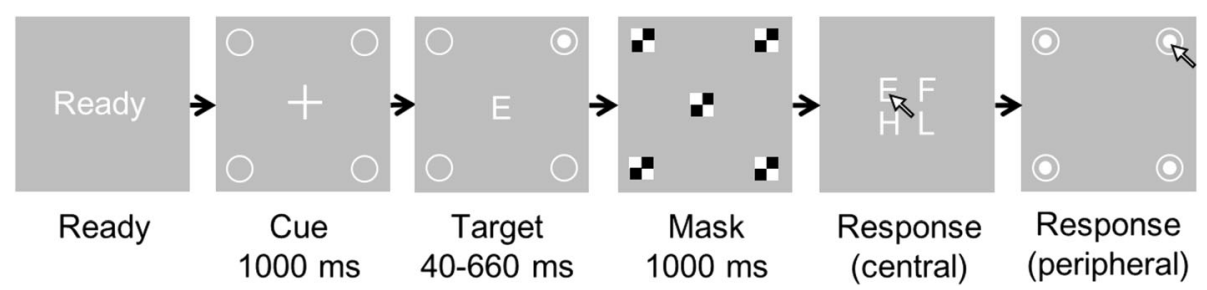

Fig. 1 Stimuli in the useful field of view test. The target stimulus was a letter $(E, F, H, o r L)$ and a filled circle in one corner while the participant fixated on the center of the screen. After the stimuli were masked, the participant indicated the letter and circle position. The trials in which participants correctly identified both the letter and the position were considered to be correct 
At the beginning of each trial, the word "Ready" appeared at the center of the monitor. When the participant pressed a mouse button, a fixation crosshair appeared, with four open circles at the corners of the screen (eccentricity $=12.6^{\circ}$ ). After $1000 \mathrm{~ms}$, the fixation cross was replaced with a letter $(\mathrm{E}, \mathrm{F}, \mathrm{H}$, or $\mathrm{L})$ as a central target, and a solid circle was simultaneously presented inside one of the open circles as a peripheral target. The target duration was randomly selected from $40,60,100,180,340$, and $660 \mathrm{~ms}$. The central letter and all four circles were then masked with a checkerboard pattern for $1000 \mathrm{~ms}$, after which the participant was instructed to use the mouse to indicate the central target letter and the position of the peripheral target. One session consisted of 48 trials. The participants completed six sessions, with an inter-session interval of $<10 \mathrm{~min}$. Before the sessions started, the participants practiced the task with two longer target durations (1000 and $500 \mathrm{~ms}$ ) to acclimate to the task.

The trials in which participants correctly identified both the central and peripheral targets were considered to be correct. For each target duration, the percentage of correct trials was calculated. Then a logistic model was created for the percentage of correct trials as a function of target duration using the glmfit command in Matlab 2014a (MathWorks, Inc., MA, USA) with a binomial distribution. UFOV test performance was defined as the shortest target duration with a percentage correct $\geq 53 \%$ $(=(1+1 / 16) / 2)$ on the fitted logistic function. Shorter duration represented better UFOV performance.

\section{Assessment of appetite status and physical activity}

Before the UFOV test, each participant completed the 8item CNAQ [23], which was translated into Japanese for the present study. The CNAQ included questions about subjective regular feeling of appetite, taste, sickness, mood, and meal frequency. Responses were scored with a 5-point Likert-type scale (e.g., My appetite is: $1=$ very poor, $2=$ poor, $3=$ average, $4=$ good, and $5=$ very good). After the UFOV test, participants were instructed to wear a tri-axial accelerometer (Active style Pro HJA350IT; Omron Healthcare, Kyoto, Japan) for 3-6 consecutive days to evaluate their habitual PA in free-living conditions. They wore the accelerometer on their right front waist during waking hours except during waterbased activities. The accelerometer was developed especially for the separate evaluation of non-locomotive and locomotive PA, with a wide range and high resolution of intensity [25]. The accelerometer recorded PA in metabolic equivalents (METs) for each $10 \mathrm{~s}$ time window (10 s epochs).

The recorded PA data were first divided into wear and non-wear periods, with the latter defined as periods of $\geq 60$ consecutive minutes of zero METs. The remaining periods with zero METs were assigned a value of 0.9 METs as a basal metabolic rate, in accordance with our previous study [26]. Participants with at least three valid days, with $\geq 600$ min of wear time per day, were included in the following analysis. The PA data were summarized as the accumulated time spent in each of the following categories: sedentary behavior ( $\leq 1.5$ METs), nonlocomotive and locomotive light PA (1.6-2.9 METs), non-locomotive and locomotive moderate PA (3.0-5.9 METs), and non-locomotive and locomotive vigorous PA ( $\geq 6.0 \mathrm{METs}$ ). Total non-locomotive time was the sum of light, moderate, and vigorous non-locomotive PA. Total locomotive time was similarly calculated. The breaks in sedentary behavior was the number of interruptions in sedentary behavior during which the intensity of PA increased to $>1.5$ METs [27]. Finally, the PA level (PAL), the ratio of daily total energy expenditure to basal metabolic rate in the supine position, was calculated as

$$
\mathrm{PAL}=\frac{\int_{T_{w}} I(t) d t+0.9 \int_{T_{N}} d t}{0.9 \int_{T_{W}+T_{N}} d t} \cdot k_{D I T}
$$

where $T_{W}$ and $T_{N}$ are the wear and non-wear times, respectively; $I(t)$ represents the intensity of PA (in METs) as a function of time; and $k_{D I T}$ is a constant $(1 / 0.9)$ that takes into account diet-induced thermogenesis. The daily mean of each PA parameter was calculated for each participant (see Table 1).

\section{Statistical analysis}

First, we checked the assumption of normality for the distribution of all variables in the present study using the Kolmogorov-Smirnov test with a significance level of $10 \%$. The distributions of UFOV test performance, years of education, and locomotive vigorous PA significantly deviated from the normal distribution. These variables were normalized with a $\log _{10}$ transformation prior to further statistical analysis. We added 0.01 to the locomotive vigorous PA values for all participants to avoid divergence for seven participants with zero values. Second, we performed an analysis of covariance with sex as the main effect to establish whether there were sex interactions between PA variables or CNAQ score and UFOV test performance. If there was an interaction, then the association between PA variables or CNAQ score and UFOV test performance would have been stratified by sex.

To determine whether UFOV test performance was associated with PA variables or CNAQ score, Pearson's correlation coefficients were calculated. Subsequently, a Pearson partial correlation analysis that adjusted for confounding factors was also performed for each variable. Confounders were selected by the stepwise Akaike information criterion method. The potential 
Table 1 Time spent in physical activity and the correlation with useful field of view

\begin{tabular}{|c|c|c|c|}
\hline & Mean \pm SD & $\begin{array}{l}\text { Correlation } \\
\text { coefficient }\end{array}$ & $p$ value \\
\hline Wear time (min) & $980.2 \pm 159.5$ & 0.207 & $>0.1$ \\
\hline Physical activity level & $1.69 \pm 0.18$ & -0.112 & $>0.1$ \\
\hline \multicolumn{4}{|l|}{ Sedentary behavior (SB) } \\
\hline Total SB (min) & $625.8 \pm 133.7$ & 0.330 & $>0.1$ \\
\hline \multicolumn{4}{|l|}{ Light physical activity (LPA) } \\
\hline Non-locomotive LPA (min) & $206.1 \pm 59.5$ & 0.018 & $>0.1$ \\
\hline Locomotive LPA (min) & $57.9 \pm 26.2$ & -0.237 & $>0.1$ \\
\hline Total LPA (min) & $264.0 \pm 71.2$ & -0.072 & $>0.1$ \\
\hline \multicolumn{4}{|l|}{ Moderate physical activity (MPA) } \\
\hline Non-locomotive MPA (min) & $48.0 \pm 23.2$ & -0.289 & $>0.1$ \\
\hline Locomotive MPA (min) & $41.2 \pm 30.0$ & 0.037 & $>0.1$ \\
\hline Total MPA (min) & $89.2 \pm 41.1$ & -0.135 & $>0.1$ \\
\hline \multicolumn{4}{|l|}{ Vigorous physical activity (VPA) } \\
\hline Non-locomotive VPA (min) & $0.64 \pm 0.36$ & -0.258 & $>0.1$ \\
\hline Locomotive VPA (min) & $0.49 \pm 0.93$ & & \\
\hline log (locomotive VPA + 0.01) & & -0.308 & $>0.1$ \\
\hline Total VPA (min) & $1.13 \pm 1.07$ & -0.367 & 0.071 \\
\hline Total non-locomotive time (min) & $254.8 \pm 74.8$ & -0.077 & $>0.1$ \\
\hline Total locomotive time (min) & $99.6 \pm 52.0$ & -0.104 & $>0.1$ \\
\hline Breaks in sedentary behavior & $382.1 \pm 84.9$ & 0.075 & $>0.1$ \\
\hline \multicolumn{4}{|l|}{ Step } \\
\hline Step counts (number) & $7638 \pm 4420$ & 0.050 & $>0.1$ \\
\hline Step rate (number/min) & $75.3 \pm 12.3$ & 0.334 & $>0.1$ \\
\hline
\end{tabular}

confounders were CNAQ, sex, age, years of education, and wear time of accelerometer for each PA variable and the PA variables, age, and years of education for CNAQ.

In addition, we performed a Pearson correlation analysis to examine the effects of aging on PA variables, CNAQ score, and UFOV. We also examined sex differences in PA variables, CNAQ score, and UFOV using two-sample $t$-tests.

Correlations and comparisons were considered statistically significant when $p<0.05$. All data are reported as mean $\pm S D$.

\section{Results}

\section{Participant characteristics, sex differences, and aging effects}

All participants completed the UFOV test and the mean test performance was $353.6 \pm 246.1 \mathrm{~ms}$. The participants completely answered the CNAQ, with a mean score of $30.1 \pm 2.6$. Five participants did not meet the inclusion criterion for the PA assessment (i.e., at least three valid wear days). A total of 25 participants (10 females and 15 males) were included in the subsequent analysis. Table 1 shows the mean values for the PA variables. The mean number of wear days and wear time were $4.7 \pm 1.2$ days and $980.2 \pm 159.5 \mathrm{~min} /$ day $(16.3 \pm 2.7 \mathrm{~h} /$ day $)$, respectively.

Neither UFOV nor CNAQ score differed between males and females (both $p>0.05$ ). In contrast, wear time, sedentary behavior, breaks in sedentary behavior, non-locomotive light PA, and total non-locomotive time were significantly greater in females than in males (All $p<0.05)$. No other PA variables showed a significant sex difference.

We also analyzed aging effects. PAL, total light PA, breaks in sedentary behavior, total non-locomotive time, and log UFOV test performance declined with increasing age (all $p<0.05$ ). Locomotive and non-locomotive light PA, total moderate PA, breaks in sedentary behavior, and total locomotive time tended to decrease with increasing age (all $p<0.1$ ). No significant aging effects were found for the other PA variables or CNAQ score (all $p>0.1$ ).

\section{Physical activity and UFOV test performance}

The analysis of covariance revealed no significant interaction of sex for the associations between any of the PA variables and UFOV test performance. There were no significant simple correlations between any PA variable and UFOV test performance (Table 1). However, the stepwise AIC method found that age and wear time were confounders of the correlation of UFOV test performance with locomotive and non-locomotive vigorous PA. After adjustment for age and wear time, longer non-locomotive and locomotive vigorous PA were significantly associated with better UFOV test performance $(r=-0.435$, Fig. 2a, and $r=-0.449$, Fig. 2b, respectively).

\section{Appetite status and UFOV test performance}

There was a significant interaction of sex for the association between CNAQ score and UFOV $(p<0.01)$ so the correlation analysis for CNAQ score and UFOV was stratified by sex. Among males, a higher CNAQ score was significantly correlated with better UFOV test performance $(r=-0.560, p=0.03)$. Based on the stepwise AIC method, age was a confounder. After adjustment for age, the correlation between CNAQ score and UFOV test performance became slightly stronger $(r=-0.635$, $p=0.015$; Fig. 2d). Among females, there was no significant correlation between CNAQ score and UFOV $(r=0.415, p>0.1)$. Based on the stepwise AIC method, no variables were confounders of this correlation. Figure 2c shows the age-adjusted correlation between CNAQ score and UFOV test performance for females, as was done for males $(r=0.320, p>0.1)$. 
a

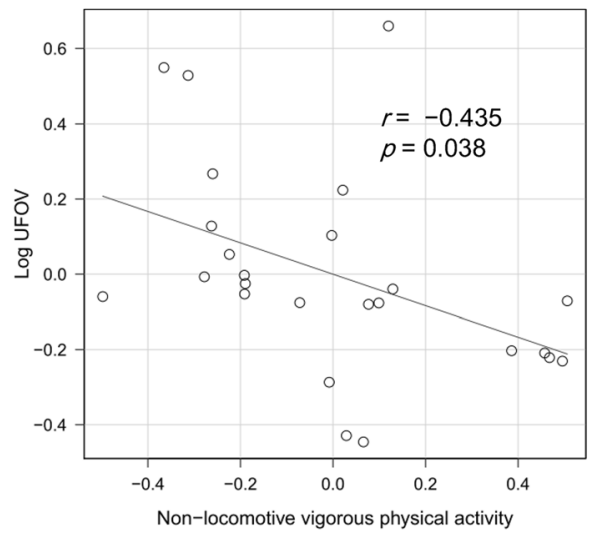

b

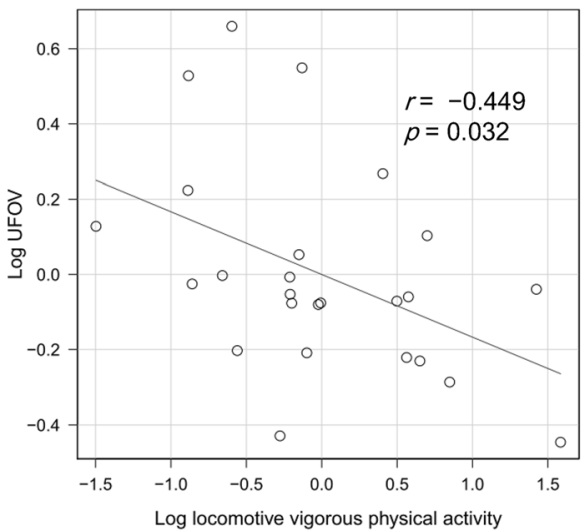

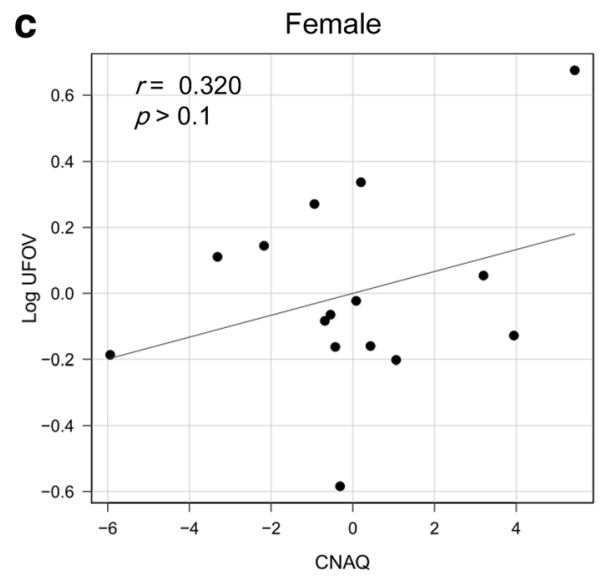

d

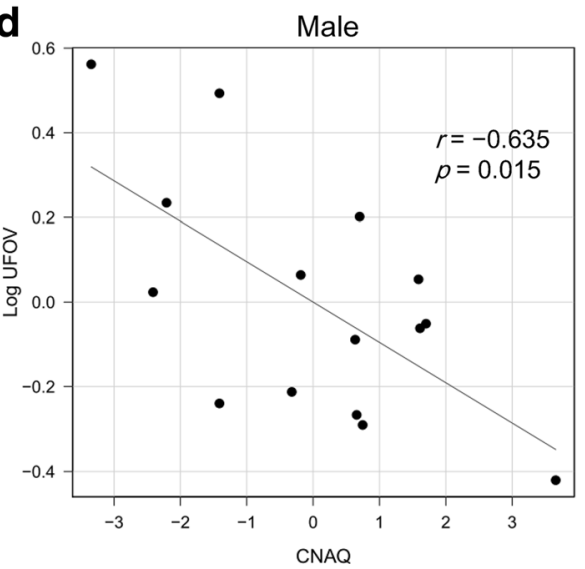

Fig. 2 Standard residual plots of lifestyle parameters vs. useful field of view (UFOV) test performance. a non-locomotive vigorous physical activity vs. log UFOV test performance, adjusted for age and wear time; b log locomotive vigorous physical activity vs. log UFOV test performance, adjusted for age and wear time; c CNAQ vs. log UFOV test performance adjusted for age (female participants); d CNAQ vs. log UFOV test performance adjusted for age (male participants). CNAQ, Council on Nutrition appetite questionnaire, used to assess appetite status

\section{Discussion}

To the best of our knowledge, the present study was the first to use a tri-axial accelerometer to investigate the association between PA and UFOV test performance in older adults. Our results showed that vigorous PA was moderately correlated with UFOV test performance in older adults, after adjustment for age and wear time. However, PAL was not correlated with UFOV test performance. This was also the first study to describe the association between appetite status and UFOV test performance. We found that better appetite status was associated with better UFOV test performance in males but not in females.

Our results suggest that PA is associated with visual function related to driving competence in older adults. More specifically, accelerometer data revealed that vigorous intensity PA ( $\geq 6$ METs) was positively associated with UFOV test performance. The PA other variables (PAL and other PA intensities) were not associated with UFOV. Recently, numerous PA researchers have advocated for increasing PAL and reducing sedentary time for health [28]. However, our study did not reveal a clear association of UFOV with PAL or sedentary behavior. This result was consistent with previous findings, using selfreported PA, that regular moderate to vigorous exercise but not total amount of PA was associated with UFOV test performance [14]. Several recent studies focused on the intensity of exercise or PA in older adults. Some of these studies found that increasing the proportion of vigorous PA reduces the risk of decline in physical functioning [29], coronary events [30], mortality from dementia [31], and all-cause mortality [32]. Recent studies of older adults also revealed a beneficial effect of high intensity intermittent training on muscle protein synthesis [33] and cardiac function in people with coronary heart disease [34] compared with traditional moderate intensity continuous aerobic training. High intensity PA may be needed to maintain visual function in older adults.

However, previous intervention studies found that exercise did not substantially improve UFOV test 
performance in older adults [35-37], which casts doubt on a causal effect of PA on UFOV test performance. This evidence has two possible interpretations. The first is that acute PA increases in later life cannot improve UFOV due to factors such as poor neural plasticity in older adults and that regular exercise throughout middle age is needed to prevent the decline in UFOV. The present study provided only a cross-sectional view of the association between PA and UFOV test performance. An active individual in the present study may have maintained PA and fitness levels throughout his or her life. In other words, adopting a fairly active lifestyle may be needed to maintain visual function before the start of its decline. The second interpretation relates to the differences in PA intensity in these studies. The present study revealed that PA at a level $>6$ METs was associated with better UFOV test performance. In contrast, the previous intervention studies only reported relative exercise intensity, if any (for example, $60-75 \%$ of the maximum heart rate). In general, it is hard to impose a level of PA $>6$ METs as an intervention for older adults because such high intensity is close to maximum capacity for a large proportion of older adults, with the exception of highly trained athletes [38]. In addition, intensive exercise is difficult to implement as an intervention task because it may result in injury, exacerbation of cardiovascular diseases, or locomotor disability. It could therefore be considered that the exercise intensity in the previous interventions was insufficient for the improvement of UFOV test performance. An intervention study that involves high intensity exercise or high intensity intermittent training in older adults is required to clarify the association between vigorous PA and UFOV test performance.

The results of the present study also suggested that appetite status was associated with visual function related to driving competence at least in older males. Recently, health concerns regarding impaired appetite regulation in older adults have become a research focus. Loss of appetite leads to a risk of reduced diet quantity and quality, which in turn may lead to conditions, such as sarcopenia, frailty, and dementia [20]. Interestingly, these appetite-related diseases occur in conjunction with cognitive impairment [39]. Similarly, there is much evidence of the beneficial effects of proper nutrition in the prevention of cognitive impairment [21]. Overall, these findings suggest an association between cognitive decline, malnutrition and appetite. It may be that visual function decline is part of an age-related functional decline due to malnutrition resulting from loss of appetite.

Questionnaire-based assessments of appetite do not necessarily represent malnutrition although a previous study found that CNAQ score might have predicted subsequent weight loss [23]. Dietary record with food weighing or blood biochemistry would be required to more directly study the association between nutritional status and UFOV performance. This is an important challenge for future research to verify the present findings.

The sex interaction in the association between appetite and UFOV is a fascinating result of this study. This result suggests that there is a different mechanism for age-related decline in visual function for each sex. However, the mechanisms for this sex interaction remain an open question, and further investigation that involves the collection of more detailed data, such as dietary records, will be needed to investigate this issue.

A possible mechanism for the association of highintensity PA and appetite with visual function related to driving competence may be brain plasticity modification. Colcombe et al. [40] indicated that aerobic exercise increased the regional gray matter volume in the brain, including in the right inferior frontal gyrus. A more recent study showed that changes in cardiorespiratory fitness due to a 12-week exercise intervention were positively correlated with cortical thickness changes in the right prefrontal regions [41]. On the other hand, a metaanalysis of patients with anorexia nervosa found reductions in regional gray matter volume in a cluster extending to the right prefrontal region [42]. According to an intervention study with UFOV training done by Scalf et al. [43], the right prefrontal region is associated with increased UFOV performance.

The present study had several limitations. Causality cannot be determined because of the cross-sectional design. The possibility that poor visual function causes poor appetite status or shorter times of vigorous PA cannot be excluded. A longitudinal cohort or intervention study would provide better understanding of the relationship between PA or CNAQ and age-related declines in visual function. In addition, the PA assessment period was short, and the sample size was relatively small. Nevertheless, sampling bias was minimized because the mean PAL in this study was similar to that in a previous Japanese study with more reliable methods $(\mathrm{PAL}=1.66 \pm 0.24)[44]$.

\section{Conclusions}

Our results suggest that high intensity PA is associated with UFOV performance in older adults. In addition, our data indicate that poor appetite status is associated with UFOV test performance in older males.

Maintaining safe and independent mobility in older adults is important for their quality of life and is also a major factor in self-reliance [45]. Recent social trend run to encouragement of voluntary return of driver's license; however, driving cessation by older drivers may not be a 
panacea to solve this issue [46]. Thus, studies aimed at extending life as a driver are required. To this end, intervention studies to demonstrate beneficial effects of daily active lifestyle on elderly driving competence are needed in future work.

\section{Abbreviations}

UFOV: Useful field of view; PA: Physical activity; CNAQ: Council on Nutrition appetite questionnaire; METs: Metabolic equivalents; PAL: Physical activity level; AIC: Akaike information criterion

\section{Acknowledgments}

We thank Junko Onishi for administrative assistance of our experiment, Nobuhiro Ippongi (OMRON PERSONNEL SERVICE Co., Ltd.) for help in the recruitment of participants, and the subjects for their participation in our study.

\section{Funding}

The TCRDL received annual research funding from its stockholder companies (Toyota Industries Corporation, Toyota Motor Corporation, Aichi Steel Corporation, JTEKT Corporation, Toyota Auto Body Co., Ltd., Toyota Tsusho Corporation, Aisin Seiki Co., Ltd., Denso Corporation, Toyota Boshoku Corporation). This study was promoted as one of the self-motivated researches of the TCRDL. Thus, the funders had no role in the study design, data collection and analysis, and the decision to publish.

\section{Availability of data and materials}

The datasets generated during and/or analyzed during the current study are available from the corresponding authors on reasonable request.

\section{Authors' contributions}

$T A, H S$, and $Y U$ contributed to design of the experiment. TA conducted experiment. TA and YU acquired and analyzed data. TA was a major contributor in writing manuscript. HS and YU cooperated with performing the experiment and writing the manuscript. All authors read and approved the final manuscript

\section{Authors' information}

TA is currently affiliated with the Obesity and Diabetes Clinical Research Section, Phoenix Epidemiology and Clinical Research Branch, National Institute of Diabetes and Digestive and Kidney Diseases, National Institutes of Health, Phoenix, Arizona, USA.

\section{Competing interests}

The authors were employed by Toyota Central R\&D Labs., Inc. (TCRDL). The authors have not applied for any patent related to this study.

\section{Consent for publication}

Not applicable.

\section{Ethics approval and consent to participate}

The study protocol was approved by the Research Ethics Committee of Toyota Central Research and Development Laboratories, Inc. Written informed consent was obtained from all of the participants.

\section{Publisher's Note}

Springer Nature remains neutral with regard to jurisdictional claims in published maps and institutional affiliations.

\section{Received: 11 March 2016 Accepted: 10 April 2017}

Published online: 26 April 2017

\section{References}

1. Ichikawa M, Nakahara S, Taniguchi A. Older drivers' risks of at-fault motor vehicle collisions. Accid Anal Prev. 2015:81:120-3.

2. Kaimila B, Yamashina H, Arai A, Tamashiro H. Road traffic crashes and fatalities in Japan 2000-2010 with special reference to the elderly road user. Traffic Inj Prev. 2013;14(8):777-81.
3. Anstey KJ, Wood J, Lord S, Walker JG. Cognitive, sensory and physical factors enabling driving safety in older adults. Clin Psychol Rev. 2005;25(1):45-65.

4. Wood JM, Owsley C. Useful field of view test. Gerontology. 2014;60(4):315-8

5. Ball KK, Beard BL, Roenker DL, Miller RL, Griggs DS. Age and visual search: expanding the useful field of view. J Opt Soc Am A. 1988;5(12):2210-9.

6. Ball K, Owsley C, Sloane ME, Roenker DL, Bruni JR. Visual attention problems as a predictor of vehicle crashes in older drivers. Invest Ophthalmol Vis Sci. 1993;34(11):3110-23.

7. Owsley C, Ball K, McGwin Jr G, Sloane ME, Roenker DL, White MF, Overley ET. Visual processing impairment and risk of motor vehicle crash among older adults. JAMA. 1998;279(14):1083-8.

8. Ball K, Edwards JD, Ross LA, McGwin Jr G. Cognitive training decreases motor vehicle collision involvement of older drivers. J Am Geriatr Soc. 2010; 58(11):2107-13.

9. Ball KK, Roenker DL, Wadley VG, Edwards JD, Roth DL, McGwin Jr G, Raleigh $\mathrm{R}$, Joyce JJ, Cissell GM, Dube T. Can high-risk older drivers be identified through performance-based measures in a Department of Motor Vehicles setting? J Am Geriatr Soc. 2006;54(1):77-84.

10. Sakai H, Uchiyama Y, Takahara M, Doi S, Kubota F, Yoshimura T, Tachibana A, Kurahashi T. Is the useful field of view a good predictor of at-fault crash risk in elderly Japanese drivers? Geriatr Gerontol Int. 2015;15(5):659-65.

11. Kelly ME, Loughrey D, Lawlor BA, Robertson $I H$, Walsh C, Brennan S. The impact of exercise on the cognitive functioning of healthy older adults: a systematic review and meta-analysis. Ageing Res Rev. 2014;16:12-31.

12. Loprinzi PD, Swenor BK, Ramulu PY. Age-related macular degeneration is associated with less physical activity among US adults: cross-sectional study. Plos One. 2015;10(5):e0125394

13. Marmeleira J, Ferreira I, Melo F, Godinho M. Associations of physical activity with driving-related cognitive abilities in older drivers: an exploratory study. Percept Mot Skills. 2012;115(2):521-33.

14. Roth DL, Goode KT, Clay OJ, Ball KK. Association of physical activity and visual attention in older adults. J Aging Health. 2003:15(3):534-47.

15. Owsley C, McGwin Jr G. Association between visual attention and mobility in older adults. J Am Geriatr Soc. 2004;52(11):1901-6.

16. Dhurandhar NV, Schoeller D, Brown AW, Heymsfield SB, Thomas D, Sorensen TI, Speakman JR, Jeansonne M, Allison DB. Energy balance measurement working G: energy balance measurement: when something is not better than nothing. Int J Obes. 2015;39(7):1109-13.

17. Helmerhorst HJ, Brage S, Warren J, Besson H, Ekelund U. A systematic review of reliability and objective criterion-related validity of physical activity questionnaires. Int J Behav Nutr Phys Act. 2012;9:103.

18. Landi F, Calvani R, Tosato M, Martone AM, Ortolani E, Savera G, Sisto A, Marzetti E. Anorexia of aging: risk factors, consequences, and potential treatments. Nutrients. 2016;8(2):69.

19. Visvanathan R, Chapman IM. Undernutrition and anorexia in the older person. Gastroenterol Clin N Am. 2009;38(3):393-409.

20. Volkert D. Malnutrition in older adults - urgent need for action: a plea for improving the nutritional situation of older adults. Gerontology. 2013; 59(4):328-33.

21. van de Rest O, Berendsen AA, Haveman-Nies A, de Groot LC. Dietary patterns, cognitive decline, and dementia: a systematic review. Adv Nutr. 2015;6(2):154-68.

22. Ohrmann P, Kersting A, Suslow T, Lalee-Mentzel J, Donges US, Fiebich M, Arolt V, Heindel W, Pfleiderer B. Proton magnetic resonance spectroscopy in anorexia nervosa: correlations with cognition. Neuroreport. 2004;15(3):549-53.

23. Wilson MM, Thomas DR, Rubenstein LZ, Chibnall JT, Anderson S, Baxi A, Diebold MR, Morley JE. Appetite assessment: simple appetite questionnaire predicts weight loss in community-dwelling adults and nursing home residents. Am J Clin Nutr. 2005;82(5):1074-81.

24. Sekuler AB, Bennett PJ, Mamelak M. Effects of aging on the useful field of view. Exp Aging Res. 2000;26(2):103-20.

25. Ohkawara K, Oshima Y, Hikihara Y, Ishikawa-Takata K, Tabata I, Tanaka S. Real-time estimation of daily physical activity intensity by a triaxial accelerometer and a gravity-removal classification algorithm. Br J Nutr. 2011:105(11):1681-91.

26. Ando T, Usui C, Ohkawara K, Miyake R, Miyashita M, Park J, Ezaki O, Higuchi M, Tanaka S. Effects of intermittent physical activity on fat utilization over a whole day. Med Sci Sports Exerc. 2013;45(7):1410-8.

27. Bankoski A, Harris TB, MCClain Jلر, Brychta RJ, Caserotti P, Chen KY, Berrigan D, Troiano RP, Koster A. Sedentary activity associated with 
metabolic syndrome independent of physical activity. Diabetes Care 2011;34(2):497-503.

28. Kohl 3rd HW, Craig CL, Lambert EV, Inoue S, Alkandari JR, Leetongin G, Kahlmeier S. Lancet physical activity series working G: the pandemic of physical inactivity: global action for public health. Lancet. 2012;380(9838): 294-305.

29. Gebel K, Ding D, Bauman AE. Volume and intensity of physical activity in a large population-based cohort of middle-aged and older Australians: prospective relationships with weight gain, and physical function. Prev Med. 2014;60:131-3.

30. Talbot LA, Morrell CH, Metter EJ, Fleg JL. Comparison of cardiorespiratory fitness versus leisure time physical activity as predictors of coronary events in men aged $<$ or $=65$ years and $>65$ years. Am J Cardiol. 2002; 89(10):1187-92.

31. Iso-Markku P, Waller K, Kujala UM, Kaprio J. Physical activity and dementia: long-term follow-up study of adult twins. Ann Med. 2015;47(2):81-7.

32. Gebel K, Ding D, Chey T, Stamatakis E, Brown WJ, Bauman AE. Effect of moderate to vigorous physical activity on all-cause mortality in middle-aged and older Australians. JAMA Intern Med. 2015;175(6):970-7.

33. Bell KE, Seguin C, Parise G, Baker SK, Phillips SM. Day-to-day changes in muscle protein synthesis in recovery from resistance, aerobic, and highintensity interval exercise in older men. J Gerontol A Biol Sci Med Sci. 2015;70(8):1024-9.

34. Cardozo GG, Oliveira RB, Farinatti PT. Effects of high intensity interval versus moderate continuous training on markers of ventilatory and cardiac efficiency in coronary heart disease patients. ScientificWorldJournal. 2015;2015:192479.

35. Barnes DE, Santos-Modesitt W, Poelke G, Kramer AF, Castro C, Middleton LE, Yaffe K. The mental activity and eXercise (MAX) trial: a randomized controlled trial to enhance cognitive function in older adults. JAMA Intern Med. 2013;173(9):797-804.

36. Marmeleira JF, Godinho MB, Fernandes OM. The effects of an exercise program on several abilities associated with driving performance in older adults. Accid Anal Prev. 2009;41(1):90-7.

37. Oken BS, Zajdel D, Kishiyama S, Flegal K, Dehen C, Haas M, Kraemer DF, Lawrence J, Leyva J. Randomized, controlled, 6-month trial of yoga in healthy seniors: effects on cognition and quality of life. Altern Ther Health Med. 2006;12(1):40-7.

38. Carrick-Ranson G, Hastings JL, Bhella PS, Fujimoto N, Shibata S, Palmer MD, Boyd K, Livingston S, Dijk E, Levine BD. The effect of lifelong exercise dose on cardiovascular function during exercise. J Appl Physiol (1985). 2014;116(7):736-45.

39. Robertson DA, Savva GM, Kenny RA. Frailty and cognitive impairment-a review of the evidence and causal mechanisms. Ageing Res Rev. 2013;12(4):840-51

40. Colcombe SJ, Erickson KI, Scalf PE, Kim JS, Prakash R, McAuley E, Elavsky S, Marquez DX, Hu L, Kramer AF. Aerobic exercise training increases brain volume in aging humans. J Gerontol A Biol Sci Med Sci. 2006;61(11):1166-70.

41. Reiter K, Nielson KA, Smith TJ, Weiss LR, Alfini AJ, Smith JC. Improved Cardiorespiratory fitness is associated with increased cortical thickness in mild cognitive impairment. J Int Neuropsychol Soc. 2015;21(10):757-67.

42. Titova OE, Hjorth OC, Schioth HB, Brooks SJ. Anorexia nervosa is linked to reduced brain structure in reward and somatosensory regions: a metaanalysis of VBM studies. BMC Psychiatry. 2013;13:110.

43. Scalf PE, Colcombe SJ, McCarley JS, Erickson Kl, Alvarado M, Kim JS, Wadhwa RP, Kramer AF: The neural correlates of an expanded functional field of view. J Gerontol B Psychol Sci Soc Sci 2007, 62 Spec No 1:32-44.

44. Yamada Y, Yokoyama K, Noriyasu R, Osaki T, Adachi T, Itoi A, Naito Y, Morimoto T, Kimura M, Oda S. Light-intensity activities are important for estimating physical activity energy expenditure using uniaxial and triaxial accelerometers. Eur J Appl Physiol. 2009:105(1):141-52.

45. La Grow S, Yeung P, Towers A, Alpass F, Stephens C. The impact of mobility on quality of life among older persons. J Aging Health. 2013;25(5):723-36.

46. O'Connor ML, Edwards JD, Waters MP, Hudak EM, Valdes EG. Mediators of the association between driving cessation and mortality among older adults. J Aging Health. 2013;25(8 Suppl):249S-69S.

\section{Submit your next manuscript to BioMed Central and we will help you at every step:}

- We accept pre-submission inquiries

- Our selector tool helps you to find the most relevant journal

- We provide round the clock customer support

- Convenient online submission

- Thorough peer review

- Inclusion in PubMed and all major indexing services

- Maximum visibility for your research

Submit your manuscript at www.biomedcentral.com/submit
Biomed Central 